\title{
Haemorrhage following Pancreatoduodenectomy: The Importance of Surgery
}

\author{
S. Connor \\ Department of Surgery, Christchurch Hospital, Christchurch, New Zealand
}

With the development of specialist centres, mortality following pancreatoduodenectomy has fallen to below $5 \%$, yet morbidity remains between 30 and $50 \%$ [1-3]. Major haemorrhage following pancreatoduodenectomy makes a significant contribution to this ongoing morbidity and mortality [3]. Significant haemorrhage following pancreatoduodenectomy occurs in less than $10 \%[2,3]$ of patients, thus identifying risk factors and determining the subsequent optimal management can be difficult unless large series are analyzed. In this issue of Digestive Surgery, two such series $[4,5]$ are presented.

Koukoutsis et al. [4] report on a large series $(n=362)$ of consecutive pancreatoduodenectomies over a 4-year period. Haemorrhage occurred in $8.8 \%(\mathrm{n}=32)$ of patients, with a $47 \%(\mathrm{n}=15)$ associated mortality. The authors [4] divided post-operative haemorrhage into 'primary haemorrhage', defined as occurring within the first week and usually due to technical issues involving haemostasis, and 'secondary haemorrhage', defined as occurring later due to sepsis and ruptured pseudo-aneurysms. (More correctly perhaps the authors should have defined primary haemorrhage as that occurring within $24 \mathrm{~h}$, and then early and late secondary - but we shall keep to their definition). Primary haemorrhage occurred in 18 of the 32 patients who suffered post-operative bleeding and, strikingly, 6 of these 18 patients died. Of the 18 patients in this group, 5 suffered a pancreatic anastomotic leak, 7 an intra-abdominal abscess and 6 had evidence of sepsis.

\section{KARGER \\ Fax +4161306 1234 E-Mail karger@karger.ch} www.karger.com

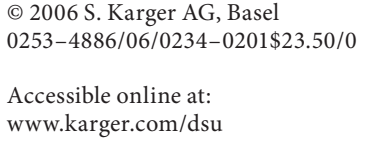

Koukoutsis et al. [4] subsequently analyzed risk factors in predicting post-operative haemorrhage, particularly secondary haemorrhage, yet they do not provide the raw data to allow an in-depth analysis of these factors, for example the number of patients who had a sentinel bleed but did not have a post-operative bleed, or the total number of patients in the series who had an anastomotic leak. This, combined with the question over the grouping of these patients and the lack of multivariate analysis (although the small numbers limit its use) questions how much can be extracted from these results. However, importantly, the sign of a herald bleed should prompt further investigation, preferably a contrast-enhanced CT scan with CT angiography $[4,6]$. Any collections or uncontrolled anastomotic leaks should be promptly drained, while any pseudo-aneurysms should be embolized.

Busch et al. [6] also recommend angiography in those with massive intra-abdominal haemorrhage, as operating on these patients can be a formidable undertaking with a high mortality $[4,7]$; yet data from their own unit indicated a bias toward surgical intervention [7]. Even if embolization is successful, surgery is still likely to be required to deal with the underlying cause (anastomotic leak), but it is suggested that this is more feasible in stable patients [6]. Koukoutsis et al. [4] employed a combination of techniques to deal with post-operative bleeding and although the numbers are too small to make definitive conclusions, it is worth noting that the success of embo-
S. Connor

Department of Surgery

Christchurch Hospital

Christchurch (New Zealand)

Tel. +6433640 640, Fax +6433640 352, E-Mail saxon.connor@cdhb.govt.nz 
lization in this series was low (20\%) compared to that reported in a recent review of the literature [6].

In striking contrast, the second paper, by Wente et al. [5], describes 8 of 458 patients who underwent pancreatoduodenectomy over a 4 -year period and developed major early haemorrhage ( $<72 \mathrm{~h}$ after surgery) from the pancreatic anastomosis with no associated mortality. In this series, those with delayed haemorrhage were specifically excluded but no data on the incidence or outcome of early non-pancreatic anastomotic haemorrhage is provided. All 8 patients were managed with re-laparotomy and control of the bleeding. Wente et al. [5] describe in detail their technique, which they have developed to manage pancreatic anastomotic bleeding as the series evolved (applied in 6 of the 8 patients). This involves opening the jejunum parallel to the pancreatojejunostomy and suturing the bleeding vessel under direct vision, thus avoiding the need to redo the pancreatic anastomosis or perform a completion pancreatectomy. The technical details deserve further comment. The authors hypothesize that the cause of the bleeding is due to loss of vasospasm of small vessels on the cut surface of the pancreas. It is however possible that it could be due to the presence of active pancreatic enzymes digesting the small vessels on the cut surface of the pancreas, similar to the process seen in pseu- do-aneurysm formation in secondary haemorrhage. This might therefore be minimized by performing a duct to mucosa anastomosis, thus excluding the cut surface of the pancreas from the enteric circulation.

Koukoutsis et al. [4] described 13 patients with intraluminal haemorrhage where the policy seemed to be of conservative, then endoscopic intervention, followed by surgery with a mortality of $3 / 13$ patients. On the other hand, Wente et al. [5] described an aggressive surgical approach in 8 patients with no mortality.

There is now high-level evidence to support sub-specialization for the management of pancreatic cancer [8, 9]. One of the reasons high-volume units are likely to achieve better results is minimizing the mortality when facing major life-threatening complications such as major bleeding [10]. The experience of high-volume centres provides critically important learning points in the management of these uncommon but potentially lethal complications.

In summary both of these papers provide useful information on the management of this serious complication following pancreatoduodenectomy and would suggest that the importance of surgery in the management of post-operative haemorrhage should not be underestimated.

\section{References}

1 Wagner M, Redaelli C, Lietz M, Seiler CA, Friess H, Buchler MW: Curative resection is the single most important factor determining outcome in patients with pancreatic adenocarcinoma. Br J Surg 2004;91:586-594.

2 Seiler CA, Wagner M, Bachmann T, Redaelli CA, Schmied B, Uhl W, Friess H, Buchler MW: Randomized clinical trial of pyloruspreserving duodenopancreatectomy versus classical Whipple resection - long-term results. Br J Surg 2005;92:547-556.

3 Bassi C, Falconi M, Saliva R, Mascetta G, Molinari G, Pederzoli P: Management of complications after pancreaticoduodentectomy in a high volume centre: results of 150 consecutive patients. Dig Surg 2001;18:453458 .
4 Koukoutsis I, Bellagamba R, Morris-Stiff G, Wickremesekera S, Coldham C, Wigmore SJ, Mayer AD, Mirza DF, Buckels JAC, Bramhall SR: Haemorrhage following pancreaticoduodenectomy: risk factors and the importance of sentinel bleed. Dig Surg 2006; 23:224-228.

5 Wente MN, Shrikhande SV, Kleef J, Muller MW, Gutt CN, Buchler MW, Friess H: Management of early hemorrhage from pancreatic anastomoses after pancreatoduodenectomy. Dig Surg 2006;23:203-208.

6 De Castro SM, Busch OR, Gouma DJ: Management of bleeding and leakage after pancreatic surgery. Best Pract Res Clin Gastroenterol 2004;18:847-864.

7 De Castro SM, Kuhlmann KF, Busch OR, van Delden OM, Lameris JS, van Gulik TM, Obertop H, Gouma DJ: Delayed massive haemorrhage after pancreatic and biliary surgery: embolization or surgery? Ann Surg 2005;241:85-91.
8 Van Heek NT, Kuhlmann KF, Scholten RJ, de Castro SM, Busch OR, van Gulik TM, Obertop H, Gouma DJ: Hospital volume and mortality after pancreatic resection: a systematic review and an evaluation of intervention in the Netherlands. Ann Surg 2005;242:781788

9 Parks RW, Bettschart V, Frame S, Stockton DL, Brewster DH, Garden OJ: Benefits of specialisation in the management of pancreatic cancer: results of a Scottish populationbased study. Br J Cancer 2004;91:459-465.

10 Glasgow RE, Mulvihill SJ: Hospital volume influences outcome in patients undergoing pancreatic resection for cancer. West J Med 1996;165:294-300. 